\title{
Source parameters determination for earthquakes in Kushiro, Japan considering source time function*
}

\author{
Lifen Zhang ${ }^{1,2, \uparrow}$ Wulin Liao ${ }^{1}$ Guichun Wei ${ }^{1}$ \\ Jinggang $\mathrm{Li}^{1}$ and Qiuliang Wang ${ }^{1}$ \\ ${ }^{1}$ Institute of Seismology, China Earthquake Administration, Wuhan 430071, China \\ ${ }^{2}$ Institute of Geophysics, China Earthquake Administration, Beijing 100081, China
}

\begin{abstract}
This paper applies a new formulation to do moment tensor inversion for earthquakes in the Kushiro area of Japan. Comparing with conventional moment tensor inversion method, the new one takes the effect of source time function into consideration. For the inversion, best solution is obtained by minimizing the difference between the observed seismograms and the synthetic ones. And the best-fitting focal depth is determined from the variance reduction. The results indicate that half duration of source time function is proportional to the magnitude of earthquakes. Large earthquakes have long half duration, whereas that of moderate-small earthquakes is comparatively shorter. The focal mechanisms of all three earthquakes are of thrust fault type, which is mainly ascribed to the collision of the North American plate with the Eurasia plate in the late Cretaceous or Paleogene.
\end{abstract}

Key words: moment tensor inversion; half duration; source time function; Kushiro

CLC number: P315.3 Document code: A

\section{Introduction}

Moment tensor provides key information for seismotectonic studies. As a mathematical description of equivalent forces, it can be used to study seismic source process. From the moment tensor solution, we can obtain seismic moment $\left(M_{0}\right)$, moment magnitude $\left(M_{\mathrm{W}}\right)$ and fault type of earthquakes. At present, a powerful tool for the moment tensor calculation is waveform inversion (Dziewonski et al., 1981; Kikuchi and Kanamori, 1991). And to some extent, moment tensor inversion analysis for large earthquakes has become a routine job. Correspondingly, the study on moderate earthquakes should be strengthened as well, because the occurrence rate of moderate earthquakes is higher than that of large earthquakes. Therefore, it is very important to estimate the moment tensor solutions of

\footnotetext{
* Received 17 October 2011; accepted in revised form 20 December 2011; published 10 April 2012.

† Corresponding author. e-mail: zhanglf112@163.com

(c) The Seismological Society of China, Institute of Geophysics, China Earthquake Administration, and Springer-Verlag Berlin Heidelberg 2012
}

these earthquakes in order to understand the stress field and faulting systems in local regions.

For this reason, the study on focal parameters of small-moderate earthquakes with near-source broadband data has become an active field in the study of earthquake source and made great progress (Ni et al., 1991; Wu et al., 1994). Wu et al. (1994) estimated the moment tensor solutions of 15 small-moderate aftershocks of $M_{\mathrm{S}} 6.1$ Luquan earthquake. In their study, Green's functions were calculated for a homogeneous semi-infinite elastic medium. And direct P, S and converted SP phases were identified for the inversion with reference to the synthetic seismograms. Zhou et al. (1999) obtained the moment tensor solutions for the small-moderate earthquakes of the Dongfang earthquake swarm. They considered the stratified media model in calculating synthetic seismograms and applied the generalized reflection-transmission coefficient matrix method proposed by Kennett (1983) and the discrete slowness integration method to calculate the Green's function. Based on the horizontally layered homogeneous medium model, Li et al. (2006) utilized the 
same method as that of Zhou et al. (1999) to calculate the Green's function. Xu et al. (2007) developed QuickCMT to determine the moment tensor solutions of small-moderate earthquakes occurred in the Beijing region and its vicinity in 2004 by inverting the broadband waveform data. And the Green's function calculation is same as those mentioned above. In general, the effect of source time function has been neglected (Dreger and Helmberger, 1993; Ito et al., 2006).

On September 26th, 2003 (JST), a huge Tokachi earthquake with JMA (Japan Meteorological Agency) magnitude of $M_{\mathrm{JMA}} 8.0$ occurred at Kushiro (southeast offshore of Hokkaido), and tsunami was also observed. The maximum seismic intensity of VI on JMA scale was registered in the eastern Hokkaido. Three days later, an aftershock with $M_{\mathrm{JMA}} 6.4$ occurred in this area. On November 29th, 2004, another large earthquake with $M_{\text {JMA }} 7.1$ occurred off the coast of Kushiro. JMA estimated the source parameters as follows: origin time, 03:32 (JST); epicenter, $42.944^{\circ} \mathrm{N}, 145.280^{\circ} \mathrm{E}$; depth, 48 $\mathrm{km}$. And an aftershock with $M_{\mathrm{JMA}} 4.2$ occurred on the next day (Table 1 ).

Table 1 Earthquakes occurred in Japan used in this study

\begin{tabular}{cccc}
\hline $\begin{array}{c}\text { Event } \\
\text { No. }\end{array}$ & $M_{\text {JMA }}$ & $\begin{array}{c}\text { Time (JST) } \\
\text { a-mo-d }\end{array}$ & Location \\
\hline 1 & 6.4 & $2003-09-29$ & Kushiro \\
2 & 7.1 & $2004-11-29$ & Off the coast of Kushiro \\
3 & 4.2 & $2004-11-30$ & Off the coast of Kushiro \\
\hline
\end{tabular}

\section{Methodology}

As we know, a seismic source can be represented by a moment tensor $M$ with five independent elements (because for most tectonic earthquakes, there is no volume change at the source). Then the synthetic seismogram can be calculated by linear combination of the five terms and the corresponding Green's function. And the best solution is obtained by minimizing the difference between the observed and the synthetic seismograms (Aki and Richards, 1980). In general, observed seismic waveform of component $c$ at a station $j$ due to seismic moment release in a source volume $V$ is given by

$$
u_{c j}(t)=\sum_{q=1}^{5} \iiint_{V} \widetilde{G}_{c j q}(t, \xi) * \widetilde{M}_{q}(t, \xi) \mathrm{d} \xi+e_{c j}^{\prime}(t),
$$

where $\widetilde{G}$ is the Green's function of basis moment tensor (Kikuchi and Kanamori, 1991), $\widetilde{M}$ is a spatio-temporal moment density function, and $e$ is an observed error.

In this study, we take the effect of the source time function into account, which has been neglected in predominant program sets with near source seismograms. To obtain stable moment tensor solutions, the most simple point source model is assumed. In addition, we assume the focal mechanism keeps constant during an earthquake, and the source time function is an isosceles triangle with half duration of $t_{\mathrm{r}}$. Based on the assumption, equation (1) was rewritten as

$$
\begin{gathered}
u_{c j}(t)=\sum_{q=1}^{5} \iiint_{V} m_{q}(t, \xi) \times \\
{\left[\widetilde{G}_{c j q}\left(t, \xi_{\mathrm{c}}\right) * T\left(t, t_{\mathrm{r}}\right)\right]+e_{c j}(t),}
\end{gathered}
$$

where $\widetilde{G}$ is the Green's function of basis moment tensor, $T$ is a source time function with half duration of $t_{\mathrm{r}}, \xi_{\mathrm{c}}$ is the location of centroid, and $e$ contains the observed and modeling errors. By comparison of equation (1) and equation (2), it is easy to find that the difference between the conventional method and the modified one. The latter considers the effect of the source time function.

For simplicity, the relationship between the observed seismic waveforms and the synthetic ones can be represented in vector form as

$$
\boldsymbol{d}=\boldsymbol{A}\left(t_{\mathrm{r}}, \xi_{\mathrm{c}}\right) \boldsymbol{m}+\boldsymbol{e} .
$$

The solution for the above matrix equation can be obtained by least squares method.

$$
\sigma=\frac{\left(\boldsymbol{W}_{\mathrm{obs}}-\boldsymbol{W}_{\mathrm{syn}}\right)^{2}}{\boldsymbol{W}_{\mathrm{obs}}^{2}}=\frac{\sum(\boldsymbol{d}-\boldsymbol{A} \boldsymbol{m})^{2}}{\sum \boldsymbol{d}^{2}},
$$

where $\boldsymbol{d}$ and $\boldsymbol{A}$ are data and error vectors, respectively. $\boldsymbol{m}$ is a model parameter vector. $\boldsymbol{W}_{\text {obs }}$ and $\boldsymbol{W}_{\text {syn }}$ are the observed and synthetic waveform, respectively.

In this study, we assume that horizontal location of centroid could approximate to the epicenter, and estimate optimal depth of the centroid and half duration using the grid-search method, variance $(\sigma)$ is used for evaluation of the results.

\section{Data and Green's function}

In this study, we use local seismic data recorded by three broadband F-net stations to calculate the moment tensors for three earthquakes occurred in Japan. For each station, all three components are considered. The data are processed using band-pass filter to mitigate the effect resulted from the heterogeneity of the local velocity structure, and the data are resampled with $1 \mathrm{~Hz}$ or $0.5 \mathrm{~Hz}$. After trials, we select the proper filtering 
rang $0.01-0.04 \mathrm{~Hz}, 0.02-0.05 \mathrm{~Hz}$ and $0.01-0.05 \mathrm{~Hz}$ for events 1, 2, and 3. Here, the raw observed data were corrected for seismometer responses and converted to ground velocity motions. For the Green's function calculation, we utilized the discrete wave number method developed by Kohketsu (1985) with the simple J-B structure.

\section{Moment tensor inversion}

After calculation, we obtain the moment tensor solutions of the three earthquakes. Figure 1 shows the focal mechanism and the comparison between the observed waveform (black line) and the synthetic waveform (red line) for each event.

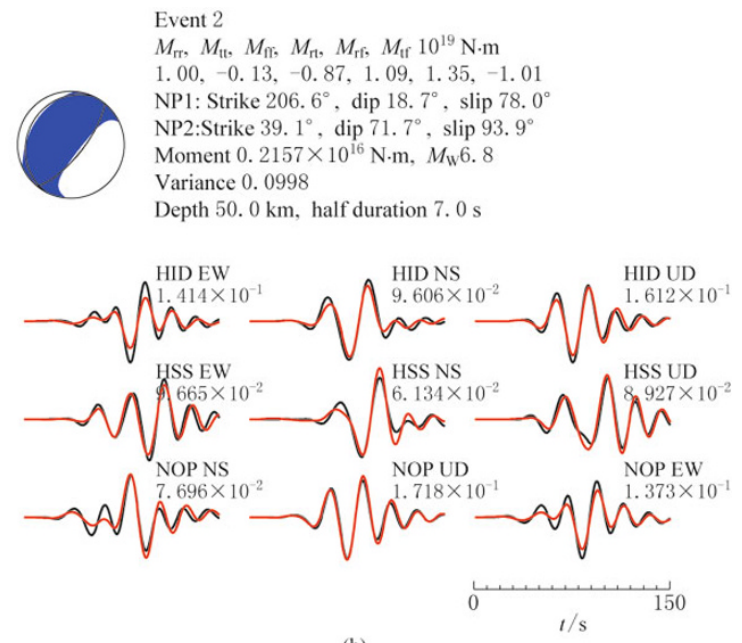

(b)

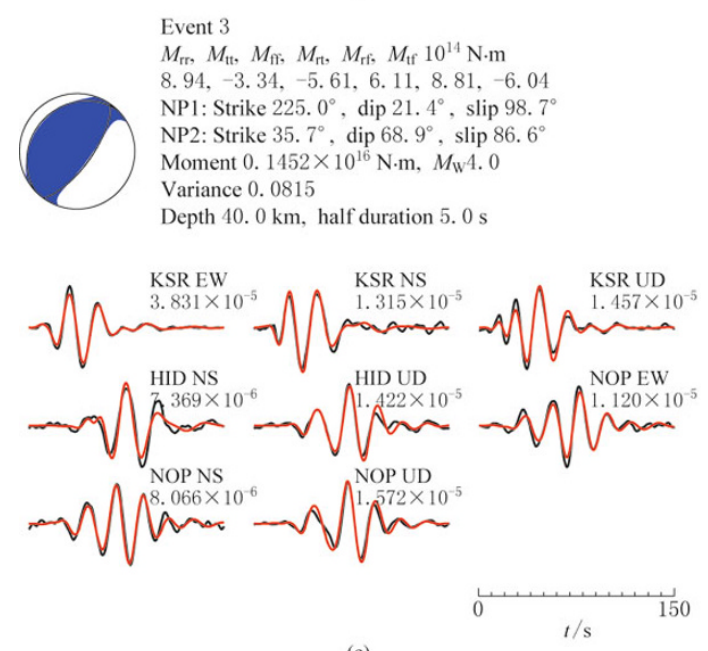

(c)

Figure 1 Results of moment tensor inversion for three events. For each case, the focal mechanism (beach ball), the source parameter information, observed (black lines) and synthetic (red lines) waveforms are shown. The station codes are given as well. And the numbers below the station code indicate the maximum amplitude in unit of $\mathrm{cm} / \mathrm{s}$. (a) Event 1 with moment magnitude of 6.3 occurred on 29 September 2003. (b) Event 2 with moment magnitude of 6.8 occurred on 29 November 2004. (c) Event 3 with moment magnitude of 4.0 occurred on 30 November 2004.

In addition, we can obtain the relationship among the depth of centroid, half duration of source time function, and variance for each event (Figures 2a-2c). Based on the methodology, we determined the final half duration time and depth according to the minimum variance. Comparison between the three figures indicates that different magnitude corresponds to different pa- rameters.

For event 1 with $M_{\mathrm{W}} 6.3$, the half duration time is around $5.0 \mathrm{~s}$, and the centroid depth is $35.0 \mathrm{~km}$. However, when the magnitude became smaller, the half duration time also became shorter. As for event 3 with $M_{\mathrm{W}} 4.0$, the half duration time is $4.0 \mathrm{~s}$, and the centroid depth is $40.0 \mathrm{~km}$. And for larger event, like event 2 with 

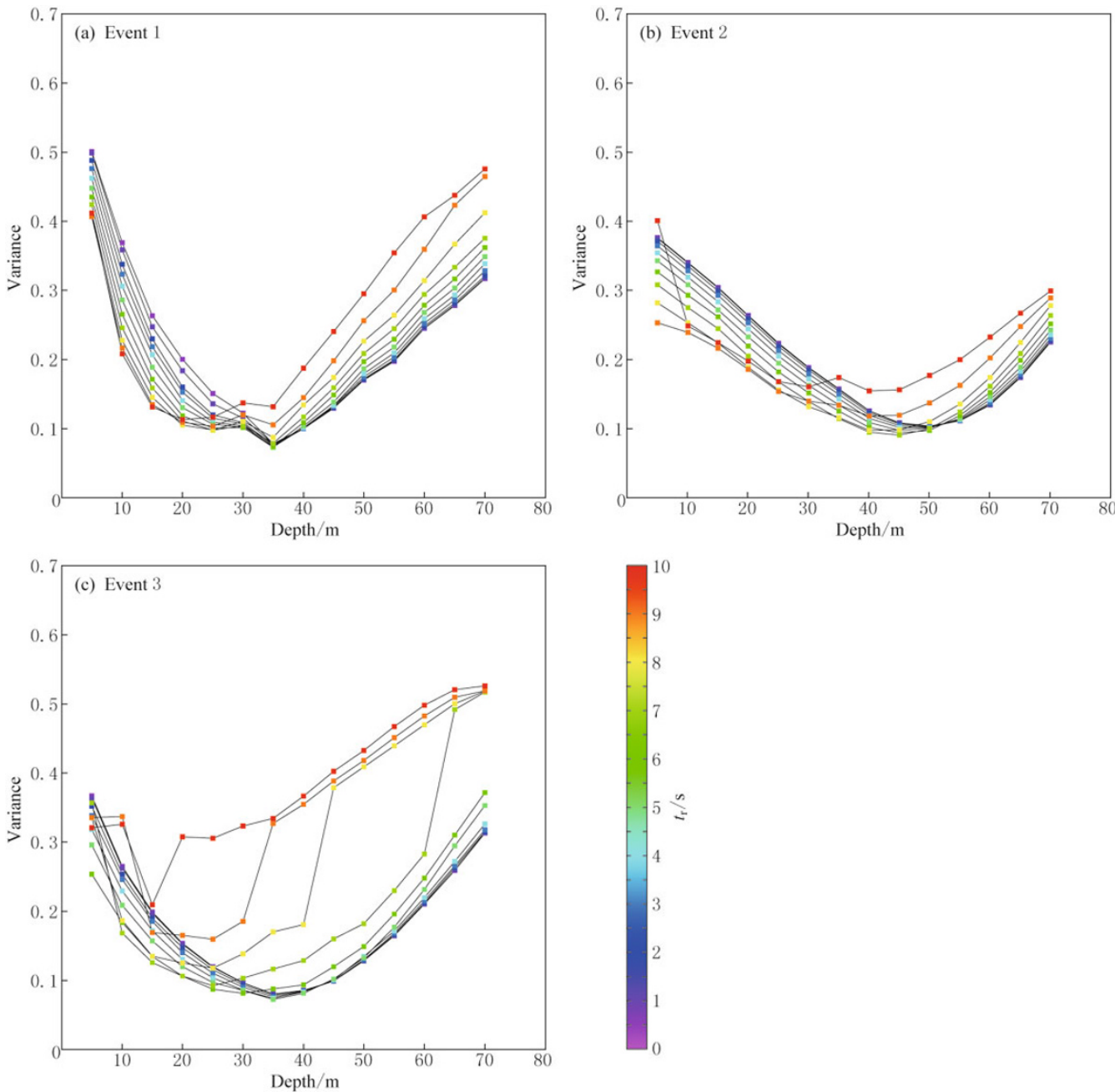

Figure 2 Relationship between the focal depth and variance on different half durations $\left(t_{\mathrm{r}}\right)$ for the three events.

$M_{\mathrm{W}} 6.8$, the half duration time is obviously longer $(7.0 \mathrm{~s})$, and the centroid depth is $50.0 \mathrm{~km}$.

\section{Discussion and conclusions}

\subsection{Evaluation of half duration time and cen- troid depth}

As mentioned above, using the new formulation provided by Yagi (2004), the moment tensor solutions for the three earthquakes have been recalculated. In or- der to examine the differences between the two methods, Table 2 lists the results from this study and Ito et al. (2004).

The variance in Table 2 shows that the wavefor$\mathrm{m}$ fitting in this study is better than the conventional formulation results. Also we can notice that the half duration of source time function increases with the seismic moment, which means that the duration time of the large earthquake is longer than that of moderate-small earthquakes. Therefore, in this case, it is reasonable

Table 2 Comparison of source parameters between our result and conventional result

\begin{tabular}{|c|c|c|c|c|c|}
\hline Event No. & Result & Seismic moment $/(\mathrm{N} \cdot \mathrm{m})$ & Depth/km & Half duration/s & Variance \\
\hline \multirow{2}{*}{1} & This study & $3.39 \times 10^{18}$ & 35.0 & 5.0 & 0.0729 \\
\hline & Ito et al. (2004) & $5.54 \times 10^{18}$ & 35.0 & $\mathrm{~N} / \mathrm{A}$ & 0.1400 \\
\hline \multirow{2}{*}{2} & This study & $2.16 \times 10^{19}$ & 50.0 & 7.0 & 0.0998 \\
\hline & Ito et al. (2004) & $3.18 \times 10^{19}$ & 50.0 & $\mathrm{~N} / \mathrm{A}$ & 0.1390 \\
\hline \multirow{2}{*}{3} & This study & $1.45 \times 10^{15}$ & 40.0 & 4.0 & 0.0815 \\
\hline & Ito et al. (2004) & $2.46 \times 10^{15}$ & 40.0 & $\mathrm{~N} / \mathrm{A}$ & 0.1040 \\
\hline
\end{tabular}


that the duration time of event $2\left(M_{\mathrm{W}} 6.8\right)$ is the longest, secondary is the event $1\left(M_{\mathrm{W}} 6.3\right)$, and event $3\left(M_{\mathrm{W}} 4.0\right)$ is the shortest. However, the estimated half duration of event 3 is $4.0 \mathrm{~s}$, which is a little longer for $M_{\mathrm{W}} 4.0$ earthquake. Because the variance of the low frequency is insensitive to the half duration value, so it will have big estimation errors.

In this study, the best waveform fitting for the three events were separately obtained for a depth of 35 $\mathrm{km}, 50 \mathrm{~km}$ and $40 \mathrm{~km}$. Because in this program, point source model is assumed, so the depth corresponds to the centroid depth of the entire fault motion.

As we know, focal depth is a source parameter which is difficult to be determined accurately. In this program, it is determined iteratively by performing inversions with Green's functions for several focal depths.

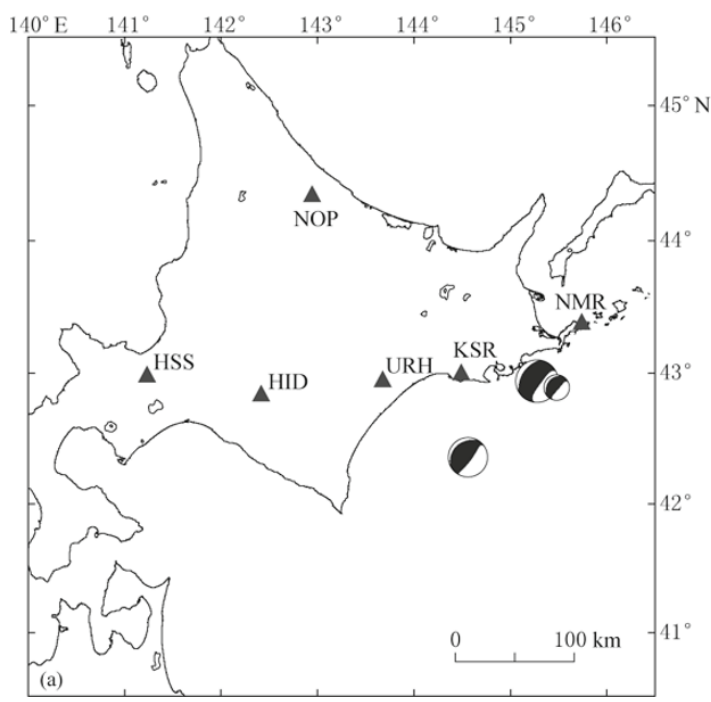

The best-fitting focal depth is determined from the variance reduction. Since the centroid depth is not adequately constrained by the local seismological network, we changed the hypocentral depth from 5 to $70 \mathrm{~km}$ in the inversion procedure with the fault mechanism and epicenter fixed, and found its minimum variance at the corresponding depth. Table 1 shows that the depth determined by different methods are almost same, and are also consistent with the actual depth, therefore, the depth resolutions for the three earthquakes are good.

\subsection{Focal mechanism and hypocenter location}

From Figure 1, it is easy to find that the focal mechanisms of the three events are typical thrust earthquakes. Referring to the location map (Figure 3), we can see these earthquakes occurred along the plate boundary.

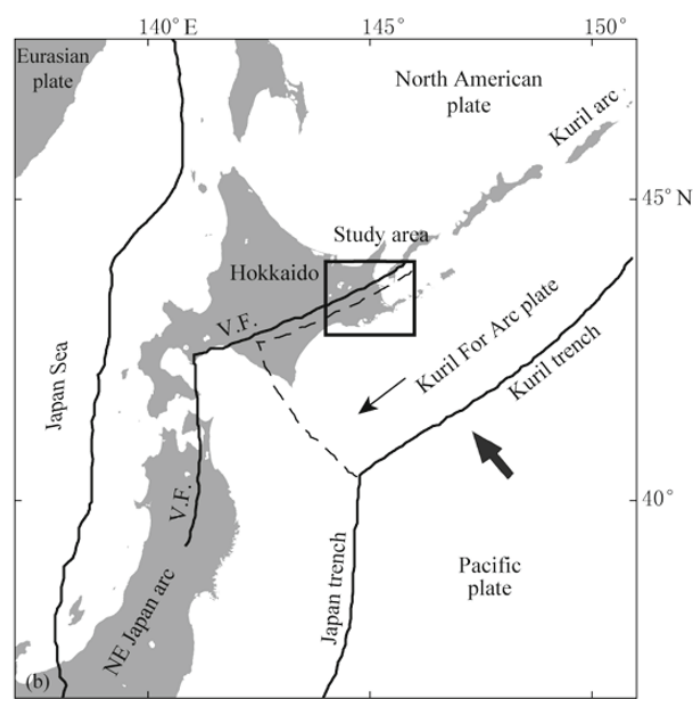

Figure 3 Focal mechanism of three earthquakes (a) and the tectonic framework in and around Hokkaido, Japan (b, after Nishida and Sugisaki, 2004). The thin arrow denotes the direction of the crustal movement causing the collision of the Kuril arc against the NE Japan arc. The bold arrow indicates the direction of the Pacific plate motion, and V.F. indicates the volcanic front.

The eastern part of Hokkaido is located at the southwestern end of the Kuril arc and is a tectonically important place where a collision of the North American plate with the Eurasia plate took place in the late Cretaceous or Paleogene. In addition to such past tectonic activity, subduction of the present Pacific plate is transforming Hokkaido, resulting in a complex tectonic setting (Figure 3) and the occurrence of large earthquakes. Triangular surveys in this region have revealed that dominant crustal contraction $\left(4 \times 10^{-7} / \mathrm{a}\right)$ with principal axis of NW-SE direction is almost perpendicular to the trench axis as shown in Figure 3. Due to this kind of compression, the focal mechanism of most earthquakes occurred in this region are of thrust faulting type. This is in agreement with the moment tensor inversion results. Therefore, considering the complex tectonic conditions, we can find why the earthquakes easily occurred in this area.

Acknowledgements We would like to express our gratitude to Professor Yuji Yagi and two anonymous reviewers for their great help and creative suggestion. Great thanks are also given to National Research Institute for Earthquake Science and Disaster Prevention of 
China for providing seismic data. This work was supported by the National Natural Science Foundation of China (Nos. 41004020 and IS201102643).

\section{References}

Aki K and Richards P G (1980). Quantitative Seismology: Theory and Methods. Freeman, San Francisco, 932pp.

Dreger D S and Helmberger D V (1993). Determination of source parameters at regional distances with single station or sparse network data. J Geophys Res 98: 8 1078125 .

Dziewonski A M, Chou T A and Woodhouse J H (1981). Determination of earthquake source parameters from waveform data for studies of global and regional seismicity. $J$ Geophys Res 86: 2 825-2 852.

Ito Y, Matsubayashi H, Kimura H, Matsumoto T, Asano Y and Sekiguchi S (2004). Spatial distribution for moment tensor solutions of the 2003 Tokachi-oki earthquake and $\left(M_{\mathrm{JMA}}=8.0\right)$ aftershocks. Earth Planets Space 56: 301306.

Ito Y, Sekiguchi S, Okada T, Honda R, Obara K and Hori S (2006). Performance of regional distance centroid moment tensor inversion applied to the 2004 mid-Niigata prefecture earthquake, Japan. Geophys J Int 167: 1 3171331.

Kennett B T N (1983). Seismic Wave Propagation in Stratified Media. Cambridge University Press, Cambridge, 339pp.

Kikuchi M and Kanamori H (1991). Inversion of complex body waves III. Bull Seismol Soc Am 81: 2 335-2 350.
Kohketsu K (1985). The extended reflectivity method for synthetic near-field seismograms. J Phys Earth 33: 121131.

Li W J, Wang P D and Chen Q F (2006). Moment tensor inversion of focal mechanism for the aftershock sequence of 1982 Lulong $M_{\mathrm{S}} 6.1$ earthquake. Acta Seismologica Sinica 19(2): 115-122.

Ni J C, Chen Y T, Wang M, Wu M X, Zhou J Y, Wang P $\mathrm{D}$ and Wu F T (1991). Moment tensor inversion of some aftershocks of the April 18, 1985 Luquan earthquake of Yunnan Province, China. Acta Seismologica Sinica 5(3): 459-467.

Nishida Y and Sugisaki Y (2004). Tectonomagnetic study in the eastern part of Hokkaido, NE Japan: Discrepancy between observed and calculated results. Earth Planets Space 56: 1 049-1 058.

Wu Z L, Chen Y T, Ni J C, Wang P D and Wang M (1994). Moment tensor inversion of near-source broadband data. Acta Seismologica Sinica 7(2): 187-199.

Xu L S, Jiang C S, Chen Y T, Li C L and Zhang T Z (2007). Moment tensor inversion of the 2004 small-moderate size earthquakes in the capital region. Acta Seismologica Sinica 20(3): 243-253.

Yagi Y (2004). Source rupture process of the 2003 Tokai-oki earthquake determined by joint inversion of teleseismic body wave and strong ground motion data. Earth Planets Space 56: 311-316.

Zhou R M, Chen Y T and Wu Z L (1999). Moment tensor inversion for the focal mechanism of the Dongfang earthquake swarm. Acta Seismologica Sinica 12(4): 371-378. 